\title{
Keeping a Foot in the Door: Neoliberal Ideology in Subjects Who Opt Out of a Corporate Career
}

\author{
Francesco Tommasi ${ }^{1}$. Johanna L. Degen ${ }^{2}$
}

Received: 27 October 2021 / Revised: 10 February 2022 / Accepted: 11 February 2022

(C) The Author(s) 2022

\begin{abstract}
It is well researched that ideals of freedom and self-fulfillment through work are perpetuated by the neoliberal ideology that permeates subjective reasoning, meaning-making, and everyday practices. While these ideals may seem attractive and enticing to the subject, their pursuit usually leads to less secure working contracts and conditions. Thus, organizations can continue to enforce economic principles and increase pressure on workers while, at the same time, the mechanisms of liberalization and individualization make subjects - not organizations - responsible for their own success and existential survival, and for creating meaningful and happy lives. Striving to design and optimize their own personal and professional trajectories, subjects perpetuate these ideals and thus adopt the socially-validated view that opting out of a salaried job in favor of self-employment is the zenith of selfactualization. Existing research on the phenomenon of opting out emphasizes gender differences around this issue, i.e., women opt out to stay home, whereas men - if their role is even considered - do so to enhance their careers. However, this research is sparse and lacks a contextualized understanding of the phenomenon, such that we still know very little about who opts out and why. Following an explorative approach, this study looks at 20 single-case stories of subjects who opted out from corporate career tracks. We find that the decision to opt out worked out well for diligent subjects with high self-esteem, who already had successful career trajectories and who - independently of gender - viewed it as an act to free oneself from, and a fundamental critique of, corporate working conditions and values. We analyze this finding through the theoretical lens of critical psychology in order to shed light on the phenomenon of opting out and the extent to which individuals can pursue meaningfulness in life and work within the scope of neoliberal conditions, i.e., in contexts where liberal principles remain applicable to the living and working conditions achieved by subjects after they have left the corporate world.
\end{abstract}

Keywords Opting out · Corporate career · Neoliberal ideology $\cdot$ Critical psychology · Agency

Francesco Tommasi and Johanna L. Degen contributed equally to the manuscript.

Francesco Tommasi

francesco.tommasi@univr.it

Extended author information available on the last page of the article 


\section{Introduction: Opting-Out in Contemporary Neoliberalism}

Characterized by general conditions of neoliberal ideology, contemporary work is rooted in the market-driven acceleration and utilization of human labor, which hide behind seemingly positive fantasies such as the positive liberalization of the self and work (Gergen, 2011, 2014; Rose, 1996). Within these conditions, subjects and their labor are exposed to market-driven principles and pushed into the contradictory position of having to serve the economy while simultaneously pursuing what is supposed to be freedom and individualization. Seen in this way, neoliberal ideology becomes an incorporated logic of individualization, competition, and a striving for survival and success via personal outcomes and performance (Bal \& Dòci, 2018). For subjects, this neoliberal focus on personal responsibility as the key to survival impacts every aspect of existence: not only one's work, but also one's personal life becomes oriented towards measurable economic outcomes and competition as the justification for being and a measure of individual worth (Binkley, 2014; Rose, 1996). Within this logic, subjects are deemed responsible for their own life courses and living conditions, resulting in a need to optimize themselves and an individual quest to control one's own life course by creating one's own opportunities, endowing one's everyday life, and working with meaning, and doing so in ways that enable one to meet the competitive pressure not only to survive but also to thrive (ibid.). This logic fails to consider personal perception, preconditions, and chance. Rather, it makes work into a distinctive field of selfidentification and meaning in which career is a key source of individual identity and the place for self-fulfillment and individualization. The meaning of work shifts away from the utility (an instrument to satisfy an existential need) and towards the possibility of achieving a utopian ideal of self-actualization through employment, career-path individualization, and self-realization. In this scenario, the pressure of individualization and success leads subjects - identified as agentic and reflexive — to design their career paths in ways that enable them to pursue happy and meaningful lives through work. Subject to the neoliberal ideology that pervades contemporary society, they must invest heavily in their careers and workplaces if they are to meet the inter- and intra-subjective pressure to achieve individual success (e.g., pressure to achieve individual success, financial stability) by engaging in meaning-making processes and making appropriate and fortunate career decisions.

In this context, opting out of formal employment in favor of self-employment (e.g. founding a startup/ becoming an entrepreneur) to pursue an individualized career, and life is positively perceived as a symbol of individual agency, autonomy, and self-actualization (Carland et al., 1995). Neoliberal ideology views the self-employment as the expression of an ideal that promotes individual ownership of one's working life, life, and agency, including the heroic fantasy that one can build a career and business from nothing but individual skill and willpower: the liberal zenith of individualization.

The term "opting out" refers to the act of leaving a corporate career track or corporate employment on one's own terms, without pursuing an aligned employee position in another corporation or company (US Bureau of Labor Statistics, 2014). However, the literature on opting out and on the term itself is mostly reduced to a specific gender perspective, focusing on women who opt out due to family duties or on the lack of what are presumed to be typical female values in corporations (Belkin, 2003; Cossman, 2009). The narrative about women opting out is predominantly tied to highly qualified women who leave corporate career tracks in order to stay home and take care of family duties (Paustian-Underdahl et al., 2019), thereby having to choose between the neoliberal ideal of a good worker and that of the good mother (Wilton, 2017). In this sense, scholars analyze this phenomenon 
from the lens of women's equality and the less inclusive working conditions experienced by women. Some research broadens these perspectives by describing the kind of work that women tend to opt into, characterizing women's alternative life- and working styles as less masculine (Biese, 2017) and showing how women pursue what ideology perceive to me a more authentic working style (Biese \& Choroszewicz, 2019; Frkal \& Criscione-Naylor, 2021; McKie et al., 2013). Other studies discuss whether women do not actually opt out at all, but rather are being pushed out by the masculine culture of inequality (Cossman, 2009; Hoobler et al., 2009; Kossek, et al., 2016). If male opting-out is even considered, the conclusion is that men opt-out for reasons related to self-actualization - to enhance their own careers, for example, or because they feel dissatisfied (Biese, 2017). Opting out among men is theorized as a decision to leave a corporation due to personal ambition, dissatisfaction in, or a personal mismatch with one's company (Batt \& Colvin, 2011; Follmer et al., 2018; Zimmerman \& Clark, 2016).

However, these varied and often reductionist perspectives suggest that opting out as a contested phenomenon that reproduces implied stereotypical gender polarities. Moreover, they tend to neglect the role of contemporary working conditions and societal context, i.e., neoliberal ideology and the subject's scope for action, reasoning processes, and life course after opting out. In this sense, a more integrative contextualization of the phenomenon of opting out could include factors beyond the gender-dichotomic perspective and instead focus on subjective meaning-making, revealing insights not only into the act of opting out but also into the meaning of work and the role of incorporated ideology in general. Such an understanding could reveal the subjective negotiations between the individual subjects and their contexts, considering motivations, justifications, orientations, assumed conflicting interests, and life conditions. This approach would enable researchers to explore certain issues - those related to agency (i.e., the responsibility of the subject), the individualization process (i.e., career pathways), and the personal meaning of work and values under neoliberal working conditions - from the subject's stance, following the questions of who opts out, why, and how so.

\section{Method}

\section{Data Collection: First-Person Perspectives on Opting Out}

To answer our research questions, we conducted an exploratory case study involving a total of 20 participants. Each participant was required to have at least 5 years of experience in a corporation. As we learned while analyzing the demographics of our study group, before opting out all the participants had achieved hierarchical positions in which they held managerial and budgetary responsibilities. ${ }^{1}$ We recruited the sample between winter 2019 and summer 2021 using a sort of snowball principle, first drawing on the contacts in our own networks (two start-up networks from Berlin) and then getting them to recruit more contacts. Participants were contacted via email and introduced to the topic of opting out, with no further indication about the objectives of our research. Those who decided to take part in our study were informed about the terms of their participation and about how we would

\footnotetext{
1 This was not an upfront criterion, rather being relevant as findings at it hints to the fact that the successful opt out is successful.
} 
collect and use their data. We instructed the participants to write down their stories about opting out, focusing on their personal experiences. As a writing prompt, the participants were invited to tell their story of opting out from their first-person perspective in the form of a narrative of up to 5000 words. ${ }^{2}$ There was no further indication regarding style or form. Nevertheless, the word "story" included norms and assumptions - namely, a retrospectively imposed (cohesion) logic, implied tension, and plots — and these, in consequence, are probably present in the data. All of the stories handed in were included in the data, whose collection ended as a natural sample of participants being willing to take part and invest time in the project, and those who probably felt they had a story to tell.

The participants were $n=11$ male, $n=9$ female, and ranged in age from 33 to 65 years. As indicated above, they were on corporate career tracks for at least 5 and up to 26 years as managers, CEOs, or in partnership positions. $N=18$ participants had a master's degree while $n=2$ have a doctoral degree. Their post opt-out careers as self-employed persons cover a broad range of different employment branches: consulting ( $n=7$ cases), yoga teaching ( $n=1$ case), coaching ( $n=2$ cases) and therapeutic practice ( $n=1$ case), food truck owner $(n=1$ case), founders of multiple start-ups (e.g., for instance, on mobile applications, $n=5$ cases), speaker ( $n=1$ case), influencer ( $n=1$ case), and researcher/scientist ( $n=1$ case). The narratives range in length from 2800 and 6201 words, with an average of 3976 words.

\section{Data Analysis: Inductive Coding for Analyzing Subjects' Stories}

To analyze the narrative stories, we used qualitative content analysis following the approach of Mayring (1991, 2015). Qualitative content analysis allows us to build on both deductive and inductive categories while examining the stories. While deductive categories rely on theoretical knowledge and tend to impose (theoretical) assumptions onto the data, inductive categories emerge strictly from the data and thus can lead to new insights which can contribute to the initial understandings (ibid.). During the analytical procedure itself, researchers first read the stories and then sort them into categories by identifying the topics that arise; hence, each section contains several topics. In a second step, the topics are briefly described and differentiated, related to each other, and then clustered. This results in larger abstract categories, which often include several specific and condensed subcategories and assigned codes. In systematically creating these larger categories, researchers repeatedly cycle through these steps, working both inter- and cross-sectionally as well as across interviews. All subcategories are then depicted in an elaborated code tree. The analysis was conducted by a group of researchers to ensure plausibility and intersubjective accuracy. Later, a research assistant coded the comprehensive set of data in several loops, ensuring the clarity and correctness of the categories and subcategories.

\section{Findings: Subjective Perspectives on the Meaning and Process of Opting Out}

Following the analysis process, our data yielded four main categories (see Fig. 1), namely, (a) identification and profiling, (b) opting out as a fundamental critique of corporate conditions and values, (c) opting out and opting into?, and evaluating living conditions and constituting (new) values (d), the social positioning of the self.

$\overline{2}$ Translated from German by the authors. 


\begin{tabular}{|c|c|c|}
\hline Categories & Exemplary Sub-Categories & Exemplary Codes \\
\hline \multirow{2}{*}{$\begin{array}{l}\text { Identification \& } \\
\text { profiling }\end{array}$} & educational background & $\begin{array}{l}\text { "Already at the university I checked into Philosophy } \\
\text { courses here and there and now I understand why" }\end{array}$ \\
\hline & $\begin{array}{l}\text { family background \& personal } \\
\text { values }\end{array}$ & $\begin{array}{l}\text { "In my family it never mattered what one's career } \\
\text { was and I kept that for myself, it's one of my core } \\
\text { values today" }\end{array}$ \\
\hline \multirow{2}{*}{$\begin{array}{l}\text { Opting out as } \\
\text { fundamental } \\
\text { critique of corporate } \\
\text { conditions }\end{array}$} & $\begin{array}{l}\text { working and living conditions as } \\
\text { employee }\end{array}$ & $\begin{array}{l}\text { "I was working } 65 \text { hours a week, and my marriage } \\
\text { was broken, I never saw my children or dog" }\end{array}$ \\
\hline & $\begin{array}{l}\text { criticising corporate traditions } \\
\text { and settings }\end{array}$ & $\begin{array}{l}\text { "I hated the culture, the presentism and the } \\
\text { hypocrisy" }\end{array}$ \\
\hline \multirow{2}{*}{$\begin{array}{l}\text { Evaluating living } \\
\text { conditions and } \\
\text { constituting (new) } \\
\text { values }\end{array}$} & $\begin{array}{l}\text { constituting neoliberal logic } \\
\text { under new values }\end{array}$ & $\begin{array}{l}\text { "I build two companies and I reject any masculine } \\
\text { "humor' and repression, I am fed up with that from } \\
\text { corporate environment" }\end{array}$ \\
\hline & lifestyle/work & $\begin{array}{l}\text { "I work equally much or more, but on my own } \\
\text { terms"/ "I am leading my own } 12 \text { companies today" }\end{array}$ \\
\hline \multirow{2}{*}{$\begin{array}{l}\text { The social } \\
\text { positioning of the } \\
\text { self }\end{array}$} & comparison to others & $\begin{array}{l}\text { "I was one of the most successful before leaving } \\
\text { and today I own two businesses" }\end{array}$ \\
\hline & attribution patterns & $\begin{array}{l}\text { "I worked hard to make the exit possible and I } \\
\text { worked for years, it was a very long process"" }\end{array}$ \\
\hline
\end{tabular}

Fig. 1 Findings and graphical depiction of the data analysis

These main categories allow insights into the subject's inner logic and justifications in the negotiation to and positions within the social context and conditions of life. The first category, "identification and profiling," refers to the subject's identity, constituting where the subject comes from in dispositive terms, in terms of their somewhat natural character, and in terms of their social becoming and origin. The second category, "opting out as a fundamental critique of corporate conditions and values," demonstrates how the subjects negotiate with the social (work) context and free themselves from suction effects and strings, and explores how they constitute opting out as a critique of working conditions and their living conditions while they were employed. The third category, "evaluating living conditions and constituting (new) values," gives insights into the subjects' perception and evaluation of their living conditions and personal assessment of striking a balance (evaluating their own life). Here, the subjects characterize and compare their living and working conditions before and after they made the decision to opt out, explain their choices and behavior, give insights into how they are impacted by the context, and justify their life course and values. The fourth category, "social positioning of the self," carves out how subjects position themselves in comparison to others and, in so doing, depict hierarchies and prestige but also give insights into the idea of what it takes to opt out, who can do it, and why they can.

Note. For each presented category, we include both the subcategories and codes (i.e., data examples) resulting from our analysis. The comprehensive code tree and additional data examples are included in the Appendix, Tables 2 and 3.

\section{Identification and Profiling}

The identification and the self-portrayal or profile refers to both an individual's disposition, and the identity or self-portrayal that they acquire through socialization. Subjects characterize themselves as having been special their whole lives, with early influences that would later have an impact on their decision to opt out; they portray themselves as different in 
comparison to an (unspecified) norm of others. In the introductions to their stories, the subjects identify and situate themselves by reflecting on their early childhood, family and geographic demographics, socialized values and skills, and personalities. Indeed, they frame the decision to opt out in terms of the very beginning of life, intertwining references to opting out, who one is as a person, and one's whole life course.

I grew up in a very nice house in the countryside in Germany (...). In my family it didn't matter what people did for a living. $(1 ; 1-2)$

I was 20 when my father died. I am the second oldest of seven siblings, I know responsibility. $(8 ; 2-3)$

Nevertheless, the subjects view their roots as only one shaping influence on their adult disposition. They describe themselves as "naturally entrepreneurial," openminded, ambitious, and having certain specific strengths in comparison to a generalized yet unspecified other. Accordingly, they tend to view themselves as living in a state of alienation that sets them apart from supposedly average normality. "I always knew I was different and today I understand why so, I am naturally an entrepreneur and not somebody working on the clock (...) I am simply someone who has what it takes" (11; 23-25). This in turn is intertwined with the subject's feeling of being more authentic after having opted out (“Today I feel happy and like I'm in my element") $(15 ; 56)$.

By contrast, the participants reported having different and separate views on their educational pathways and the role that educational level played in leading them to pursue their dream of finding an authentic job. Although the participants broadly agreed with each other regarding their dispositive and socialized motives, their views were less aligned when discussing the more formal impact of education on their choice to opt-out. Indeed, some participants reflected on their educational experiences as wrong, possibly detrimental to entrepreneurship, and never a good fit for them personally:

It's difficult to find out where I started going off the career track. I think it must have been before I actually started my career in university. Most others had very specific goals; I only had areas that interested me. $(6 ; 2-4)$

Conversely, other subjects presented their educational background and work experiences in corporations as crucial to making possible the later act of opting out:

All of my siblings have studied either law or medicine, including me. It gave me so many insights, which I use until today" $(8 ; 3-4)$. "So my story of opting out is a plea for education. I would have never been where I am today if it wasn't for further education. No one believed I could do it and everyone laughed at me and about why I would stress about exams and today I am here and they are still back there. $(5 ; 51-52)$

In sum, the subjects frame the act of opting out as one that is intertwined with their life course - which, in turn, is conditioned by their general mode of being, by who they are as people, and by the skills that they (diligently rather than randomly) have gained through their childhood roots, life, education, and work.

\section{Opting Out as a Fundamental Critique of Corporate Values and Working Conditions}

The subjects explain their act of opting out by condemning, critiquing, and regretting their former corporate lives and working conditions, substantiating their views with concrete personal experiences. In recounting these experiences, the subjects allude to 
various factors: loss of time, lack of agency, and a lack of coherency between their own and corporate values and working conditions. Yet, as they also note, these values and working conditions represented desirable objectives when they first started their corporate careers. When reflecting retrospectively on this seeming contradiction, the subjects tend to explain it as the result of their having been blinded by the light of certain key conditions (e.g., a prestigious status, a high salary) which they describe as objectively and normatively attractive. Over the course of a few years, these formerly attractive conditions change their meaning, become foreign to the subjects, lose importance, or generally become overshadowed by the conditions of life and work and the negative effects of corporate position on both, leading to a personal state of alienation, lack of meaning, inner emptiness, dissonance, and overall dissatisfaction. It is this perceived negative state of living and working, the subject's stress, that drives their desire to free themselves from this condition by opting out.

In pointing to the objective aspects of corporate career pathways which they formerly deemed positive, the subjects point to two things: (1) salary and (2) social recognition at work (i.e., external feedback and acknowledgment) and in society in general (i.e., social status and prestige as normatively successful and self-realized), thanks to a corporate position which, especially in the first few years, is described as positive, satisfying, and a supposed dream situation. However, the participants agree that such views seem to be the outcome of flawed judgments. Indeed, all of them describe some enlightening reflections as a form of unmasking, where the dreamy profession and feasible life become foreign and suspect, revealing emptiness and logic that threatens well-being:

I truly had everything anyone could dream of. I remember how I felt very important and, at the same time, very proud when walking into the huge building where I was part of the managerial team. My salary was gigantic. At the same time, I started feeling odd. The raises came almost automatically, and I wondered what the objective of my work was, mostly networking, just being there - and that felt quickly wrong. (13; 41-45)

This might seem to immediately reduce opting out as a general reluctance of the career pathway in corporations or neoliberal logic. Tellingly, however, the participants' critique targets the habitual and structural aspects of their current corporate working conditions, and the conditions that they view as detrimental to their expressed wish to find meaningful work; it does not target the characteristics of neoliberal working conditions (i.e., long working hours, competitiveness, or individualized responsibility for success). For instance, presentism is a sort of precarious characteristic of working conditions in the economy in general.

I never mind working long hours - I work tons of hours now - but it was the fact that we had to be there, in the presumably modern glass wall offices which really meant everybody could watch every step. Overall it was awful, being there for no reason when you are done with the tasks and knowing your wife is waiting at home. It became more and more of a burden, until I did not even want to show up physically at all, and that was not about work. $(16 ; 308-312)$

In this vein, social dynamics and values related to masculinity and conservatism are suggested and revealed as counterproductive and outdated:

As a woman, I had to adapt to everything. I was successful very quickly, but only [sic] at the expense of my own values, mode of being, and gender role. The boys' club, which 
means everybody in the entire firm, was laughing about hostesses and I started hating even the less radical incidents in the form of ongoing conversations about cars. The simple fact that I was left alone to do all the emotional work for the entire department was horrific. I did not notice it in the beginning, but really everything was masculine: colors, flowers, jokes, career paths, clothing, meetings, travels, and food. (4; 156-160)

Moreover, working conditions and social traditions in the corporate landscape are described as generally lacking in "decent" $(3 ; 191)$ human behavior; relationships between the companies or supervisors and employees or managers are reported to be rather negative and inconsistent. This negative perspective on relationships refers not only to the subtleties of the atmosphere, settings, and traditions but also to concrete factors related to (structural) support and opportunities. Subjects report having felt personally neglected, unimportant, or like burdens on the corporation and others when they do not assimilate. Just as their perception shifted, making what once seemed to be attractive working conditions seem harmful, the subjects describe this situation as a factor behind their decision to opt out.

In the beginning everyone is welcome, there is mentoring and everything, then you are quickly left alone, you make suggestions but no one listens, your values, your six-year education, and expertise, all irrelevant, all that matters is to maintain what's already happening. It was very unsatisfying, unbearable. (12; 77-81)

Such an inhumane landscape resulted in the impoverishment of human relations, until employees felt unable to interact with colleagues and supervisors, resigning instead to what they experienced as an inhuman authority. That is "I didn't speak up so much anymore. My attitude and power were gone and I became a reactive robot" (1;60-61).

The subjects describe the negative effects (personal, psychological, and social) of this situation on their well-being and talk about a decline of self-worth and self-esteem.

Lastly I wondered if these long hours were actually fostering my creativity and if I was doing a better job by working that long, or the worst job due to the circumstances. I felt exhausted at times. I loved working, but a lot of the conditions were just taking away my energy and personality. I learned that nothing is about me and nothing is about the customer: it is all about the organization and its absurd traditions. $(7 ; 36-38)$

The context also contains the long-established conflicts and stereotypes of family demands, intimate needs (e.g., time for one's self or one's partner), and structure within the corporation (long working hours). One can gain a deeper perspective from what subjects say about their personal networks and relationships, i.e., about the people in their lives who reflect and communicate on how adapting to male behavior had changed the subject - and not for the better — with female workers being called "domina" and "aggressive" $(2 ; 36)$ for having adapted to the male habitus, or from the subjects' comments about their failings as a partner in the personal sphere (private life): "What I realized only later was that I was an even bigger failure as a wife" $(1 ; 36)$. "There were flexible working hours; ironically it was just the end of your career when making use of this as a woman. A man coming home late is still a great father and provider, a woman who works long hours is supposedly ineffective, neglecting her family and counts as overall unorganized, in 2020" (12; 208-209).

The subjects' critique of their living and working conditions not only enables them to justify why one would opt out: through their critique, the subjects constitute their opting out as an emancipatory act that opens the door to new conditions that support their personal values regarding life and work. 


\section{Opting Out and Opting into? Evaluating Living Conditions and Constituting (New) Values}

In recounting the process that led them to leave behind corporate life, the subjects frame their decision in specific ways. Two common themes emerge from these accounts: (a) opting-out is a concrete act, and (b) opting out opens the door to a new life, oriented towards personal values, and characterized by self-actualization. In the latter vein, the subjects look comparatively at their lives before and after opting out, focusing on how they felt and their mode of being in the world. Describing the restrictive and productive dynamics that initially kept them from opting out, they refer to these as a function of power. They also discuss the factors that led them to commit an emancipatory act of agency against those restrictive power dynamics, i.e., to opt out.

a) In the subject's accounts, the actual act of opting out is abrupt. It is either tied to a single event, which is represented as the last straw ("the straw that broke the camel's back") or represents the outcome of a long progressive process of internal and external negotiations: "I decided that there was only one solution: The hard exit. I quit the next day" (1; $73)$.

In long-term processes, the opting-out act marks the start of a long, personally, and socially challenging process of emancipation. This process has both positive and negative suction effects on the subjects' inner processes, as well as on their negotiations with norms and the external work/social context. As positive suction effects that make it hard to opt out, the subjects describe familiar (working) conditions, a high salary, social relationships with coworkers, basic existential needs, and habitual belonging. Negative suction effects that counteract the urge to opt out are described as fears about an uncertain future, existential insecurity, and possible failure.

It was hard to quit, I was sad to lose my colleagues and I was sure we would not stay in touch. I was afraid to become a large disappointment and failure. I was afraid to disappoint my family and my wife and to risk our existential base. $(16 ; 300-301)$

In deciding to leave their corporate jobs, the subjects are partially driven by negative push-factors that lead to aggression (with aggression being viewed as a force to push through one's own interests). Such factors include the perception that their working environment is unbearable, that the work itself is meaningless, and that there is an incongruence that their work does not align with their personal values. Positive pull-factors driving the same decision include optimistic and hopeful visions about a future that promises to bring relief, freedom, larger scope for creativity, authenticity, and self-actualization, and a better work-life balance: "I became actually crazy, which made it easy to finally quit and overcome all fears. I had the choice to become a zombie or run, so I ran" (14; 177-178).

Overall, the act of opting out is depicted as challenging, and the years before as deprivation. In consequence, the subjects often compensate for their suffering by traveling or furthering their education after they leave their corporate jobs. This makes the act of opting out not only a significant turning point and singularized event work-wise, but also the start of a symbolically meaningful shift in the subject's life, lifestyle, and social context before she or he opts into a new career and self-employment: "Three months later, we took the kids out of school, sold all our stuff and traveled the world for a year" $(1 ; 75-76)$. 
Table 1 Subcategories concerning life after opting out

\begin{tabular}{|c|c|}
\hline Subcategories of category 3 & Data examples \\
\hline Self and feeling & $\begin{array}{l}\text { "I work long hours, possibly even more than I have before, } \\
\text { but now it is giving me as much energy as it is taking up. } \\
\text { I feel good." (7; 54-56) }\end{array}$ \\
\hline Values and principles & $\begin{array}{l}\text { "My knowledge and my doing was used for someone else } \\
\text { but for whom" ( }) ; 189) \\
\text { "a start-up with a purpose managed by } 2 \text { female founders } \\
\text { with a vision to change how we work." }(2 ; 100-101)\end{array}$ \\
\hline $\begin{array}{l}\text { New life (judgments, i.e., as free, natural, } \\
\text { instinctive, and intuitively right) }\end{array}$ & $\begin{array}{l}\text { "I am content with myself and with what I do." }(7 ; 54) \\
\text { "But by now I am free, very happy and I enjoy my life } \\
\text { much more than before." }(4 ; 28-29)\end{array}$ \\
\hline New life (conditions, e.g., family relationships) & $\begin{array}{l}\text { "I do work even longer hours being in science but really I } \\
\text { can work whenever I want. I work nights, I work maybe } \\
60 \text { h a week, but I am together with my three girls every } \\
\text { afternoon }(\ldots) . " \text {. (5; 32-34) }\end{array}$ \\
\hline
\end{tabular}

b) With respect to the realization of personal values as a self-actualizing event, opting out is presented as ushering in a new form of life and work. The participants present a series of aspects covering both themselves and their feelings about their new lives and expectations (see Table 1). The story of opting out is intertwined with references to the subject's personal values and general lifestyle leading up to and shaping their values, as well as working conditions, the company itself, and life after opting out. The subjects describe their emotions before opting out as fairly negative and report feeling overlooked, unappreciated, sad, exhausted. They also report a feeling of inner emptiness in life and the sense that life is meaningless. Their wording changes significantly when subjects describe how they felt after the exit from corporate life. Here, they report positive emotions and feelings - happy, powerful, excited, authentic, true, relieved, and free. Fear nevertheless plays a role in the descriptions of life both before and after the act of opting out; during their corporate days, the fear is to drop out, leaving behind the security of a continuous income and a known, familiar life that one has learned to manage successfully. After leaving corporate life, the fear is grounded in existential needs - concerns about the new company and the loss of one's social and professional network. In terms of describing working conditions, the subjects describe equally long working hours for both scenarios (before and after the exit from corporate life). The difference between the two is not the amount of work/investment put into each, but the meaning of the work and the act of being true to their own values: "I only hire women, I am done with masculine workforces and my company is thriving" (12; 215-216), "I have 14 enterprises now and not a single employee of mine is working on the clock" (20; 135-136).

Contrary to the findings of existing studies on the subject, our results did not yield any gender differences. Equally many male and female participants referred to family values, and all of them named family, true flexibility, and autonomy of choice regarding when to work, rather than how much to work, as significant factors. In their accounts, male subjects may even place a higher value on family than female ones: "I had finally [through opting out] been putting my family before the firm" (male, 3; 34): "First I fixed the family house and took care of everything that had been neglected, then I turned my focus to what I could do next and bought the truck [food truck]" (male, 8; 67-68). 
If we follow the subject's meaning here, we can see opting out as the logical consequence of an evolution and growth within — and later beyond - the corporate system. All of the participants described the same basic dynamic. First, there was the thrill of success, power, lifestyle, and money: "I enjoyed traveling everywhere first class in my suit. I'm not an attractive man, but the women I got just with my business card and my expensive suits, it was almost too easy. I thought it would always go on like this" $(8 ; 41-43)$. Then, increasingly, the subject began to question the impact and, later, the meaning of their corporate career; thus, the objective criteria of success, like money, began to drop in importance as the subject began to critically question the values that she/he associated with corporate work vis-a-vis those of other people and corporate goals in general:

But after a while, I didn't laugh at all anymore. I didn't feel anything. I kept going but even the merger of two big automotive companies did not thrill me anymore. I just questioned myself, what are we doing, to our workers, each other and the world? (8; 54-57).

Regrets do nevertheless play a role: "I opted out of a corporate and executive career. I regret all the energy and every single fight. However, I have not regretted my choices to leave, even though working hours have been long and salary has been limited now I am self-employed" (3; 46-48). Other forms of regret are projected into possible future failures: "I am proud of my business, but I slept better when I was on my salary, and I can only imagine the regret and desperation if this venture goes south" (9; 411-412).

\section{The Social Positioning of the Self: "Self-esteem and the Diligent Elite"}

Opting out is for the diligent, the successful, and for those with high self-esteem. According to our analysis, those who opt out want to self-actualize, independently of social representations and the status quo. As seen above, those who opt out may have some specific characteristics or an underlying conviction that only a life outside the confines of corporate life is worth living outside the confines of a corporation. Indeed, the act of opting out is attributed to ability and will, to be brave and willing to take on risks, and to the overall effort: "I was always better and faster than anyone - it was a family thing, everybody needs to be better than everyone else, siblings as well as others" (8; 5-6). Accordingly, the subjects had high self-esteem both before and after opting out, and they were all highly successful in their corporate careers: "I was proud of being the youngest person in the extended leadership team (...), and my salary was higher than anybody else my age. And now I am proud to be among the most successful" (3; 7-9). High self-esteem does not only refer to performance and success but also to values such as a greater meaning and the willingness to take on risks: "It comes from my morality towards honest work" $(5 ; 213)$. "Everything was only possible due to my personal will to risk everything to build a morally good working environment for myself and other women" (18; 131-132).

However, this is also to say that those who are capable of making the move to opt out rely on skills gained during their corporate careers, and on the confidence, they felt when comparing themselves with their peers:

(...) back then [in the corporate context at a later stage] I understood that I could do

it. And then after some time in the company, I saw many tasks that were conducted or even outsourced that I could easily master myself and I wondered if the company still made money, based on these uncompelled tasks. And I did observe that with 
colleagues and friends. Their specialized jobs were quite plain and I could master all this myself. $(4 ; 65-69)$

Although they present themselves as independent of social representations, the participants also report feeling superior in terms of their social position, and stress that they feel just as successful and admired after having opted out: "I felt that I could not be the role model I am able to be at the fullest. My abilities were cut back, my sparkle unwanted. In my own company, I make the rules and I allow myself to sparkle and so do my employees" $(10 ; 180-182)$. While interpreting themselves as extremely successful among their peers before and after opting out, the subjects feed the idea that they are individuals who are exceptionally able to capitalize on their corporate experiences in terms of knowledge and economic and social capital.

\section{Discussion: Opting Out Goes Against Corporate Working Conditions}

This paper has sought to offer a more integrated understanding of the opting-out phenomenon which shows that women and men, independently of their gender, may choose to opt out of a working life that they view as impoverished and harmful and that they make this choice not to reduce their working hours or escape the neoliberal ideology, but rather to be true to their personal values and to enable a balanced lifestyle that leaves room for private life. The existing studies on opting out have tended to portray opting out as a process driven by gender differences, paying little attention to the context.

Our findings suggest a different perspective: that opting out is conditioned by the subjects' desire to find meaning and their urge to gain agency, coupled with their repudiation of the inhuman landscape of today's corporate environment, which they perceive as outdated (presentism, masculinity), ineffective (absurd practices) and meaningless (token tasks, neglect towards an employee's potential and that of humanity as a whole). Organizational working conditions then become an antecedent from which the subjects distance themselves as they strive to achieve greater and more autonomous success through selfemployment. Ultimately, this shift is facilitated and conditioned by individual abilities (i.e., being diligent, a born entrepreneur, and successful prior to the exit from corporate work). In contrast to current academic perspectives on the phenomenon of opting out, therefore, our findings suggest that the reasoning behind the choice to opt out may not be dependent on gender or work-family conflicts. This confirms previous arguments against gender-based perspectives on the phenomenon (Biese, 2017). Moreover, the subjective drivers of opting out depend on capital, disposition (courage, anxiety level/need for security), risk willingness, social position, self-esteem, and the resultant perceived subjective meaning, which are not exclusively reported on by males who opt out, as has been previously argued (see, Batt \& Colvin, 2011; Follmer et al., 2018; Zimmerman \& Clark, 2016).

With regard to questions of equality and chance, the participants in our study define themselves as having the ability to opt out, thanks to their natural state of being, their disposition, and their personal capital stemming from their education, corporate career, and diligence. In profiling themselves as rather special and superior vis-a-vis their peers, they do not appear to perceive their initial position as especially fortunate. Rather, they attribute their own success, both in their former career and as self-employed persons, to aspects of themselves: their competence, personal engagement, and risk willingness, and even with reference to the logic of protestant work ethic. In this sense, they position themselves 
among the most successful — as members of the elite. This suggests that opting out requires outstanding economic and symbolic capital gained from a person's demographics, socialization, and former career. Such evidence indicates that our participants incorporate the neoliberal logic of individualization and competition into their justification for opting out, arguing for a form of group differentiation and distinction in which they themselves figure as members of a select group of successful subjects - the ones who are uniquely capable of outperforming the average worker (Glynos \& Howarth, 2007; Bal \& Dòci, 2018). In short, opting out seems to stand at the nexus of the individual's desire to selfactualize/find meaning in life, and her/his personal potential in terms of self-esteem, perception of capability, and actual capital and power. Yet those who opt out seem not to rely on a novel form of emancipation from neoliberal logic; rather, they seem to express a form of work individualization that reflects this very same logic.

Our findings suggest that opting out is a way of freeing oneself from current working conditions in the corporate context, one that arises when individuals undergo an emancipatory evolution through personal experiences and crisis. Progressing in their corporate careers after starting out with dedication and enthusiasm, the participants reported experiencing a lack of meaning in work and their suffering in the face of the corporate economic logic. Despite having been part of corporations where they held a medium-to-high level of responsibilities, all of the participants reported their high level of commitment to and identification with their working environment and their support for the organizational culture. Supporting this dedication to work was their desire for social and economic recognition, which led to a high degree of achievement - interestingly, the participants often do not refer to themselves as outstanding when comparing themselves to other high-performing employees. The more their careers developed, however, the greater their sense of meaninglessness and emptiness. Indeed, both the conservative environment and the inhumane workplace relationships are pointed to by the subjects as detrimental factors within their daily experience of work. For example, all of the participants referred to a dishonest culture that followed the principle of utilization, leading them to states of alienation and to a radical decline in their well-being and functionality both in their professional and private lives. The subject's identification is disrupted, and while work which they can no longer identify remains at the core of everyday life, ambivalences lead to a state of dissonance and psychological and social breakdown emerge.

These findings indicate, with reference to power, restrictive contexts and resistive subjective scope and agency, that those who opt out use their state of crisis and dissonance as a springboard to their own emancipation from corporate conditions and values, and then create a lifestyle and working life that are imbued with new norms and an emancipatory system of personal values, while still holding on to the underlying neoliberal principles. Here, the meaning of work seems to change from a possible Marxist understanding, which stresses existential security and survival and being part of a functional system, to the more personal meanings of work that arise from the subject's stance, such as the drive towards self-actualization (Rose, 1996). In contrast to the masculinity, values, relationships, working style, and atmosphere of corporate working culture, the subjects posit alternative values that are rooted in true flexibility and autonomy in terms of time, non-masculinity, work-private life compatibility, human (personal) relationships, and even flat(ter) hierarchies. The neoliberal values that remain applicable are the orientation towards success in accordance with objective criteria as expressed in monetary terms, competition, superiority (proudly referring to success and capital as distinctive criteria), and the tendency to see one's work and profession as a source of self-identification. Work remains the center of life in terms of the amount of time invested in it, with subjects 
viewing both competitive comparison and success as distinctive criteria. The subjects continue to strive for objective success criteria after opting out of building their own companies in a competitive market with an orientation towards power. In this context, the meaning seems independent from the purpose of the company, but is based on the subject's perceived autonomy and is justified by their objective economic success. The subjects' everyday practices after opting out demonstrate the obsolescence of long-established corporate traditions, such as masculine principles, clocking, presentism, and hierarchies, viewing them as unnecessary for objective economic success, by demonstrating functional and practical alternatives within neoliberal market-driven logic.

From a critical psychologist perspective nevertheless, it becomes obvious that, in critiquing corporate traditions and settings, the subjects remain squarely situated within a neoliberal logic (i.e., Gergens, 2014; Rose, 1996). Accordingly, we find that those who opted out developed a form of restrictive behavior against corporations - but not against the system as such. This is evident in the extent to which the participants report on what they see as the restrictive and structural contexts of corporations, and in the scope for agency that they see in individual subjects, via enlightenment and change. As such, the subjects criticize presentism but not long working hours. In fact, they even voice a desire to work more and harder, and to take on more risks in terms of individualization and singularization (Gergens, 2014; Rose, 1996) despite the (often negative) consequences (Marvakis, 2019). Those consequences reveal that what would appear to be an emancipatory act of (supposed) freedom and agency is actually an acceleration of individualization and risk that also involves a loss of (social) security (ibid.). None of the subjects use the understandings they reached and their potential scope of action to change the neoliberal aspect in their mode of being. Conversely, in shifting from the corporate context to one of self-employment, they relocate neoliberal working conditions within a frame of compromised values, basing it on the same neoliberal principle, and thus retain a level of restrictive agency, in the sense put forth by Holzkamps (1983/2003, 1990; Schraube \& Højholt, 2016): "I am willing to work even harder and take more risks, as long as it is not under masculine tradition" (4; 301-302). Here, it is demonstrated that one's life conditions can be questioned to a certain extent, criticizing corporate traditions and working conditions, yet can remain restrictive (compliant) within the general neoliberal logic and system (building companies in a market-driven logic that strives towards economic success, submitting to the idea that hard work might pay off, and engaging in identification through economic superiority). This could be seen as an act of productive power, in which being heroic (freeing oneself from the corporate world) - as the subjects perceive themselves and others who opt out in the bigger picture serves to advance neoliberal logic, and in which work changes but the principles accelerate. Everyday practices, in the end, have changed in character (less masculinity and presentism) but not in mode (working and economic growth as the main driving force of life).

These findings provide an initial indication for considering opting out as an emancipatory act against corporate values and against today's workplace conditions while remaining in a liberal logic of the self (Gergen, 2014; Rose, 1996). However, our argument of opting out as a form of work individualization should be interpreted with some caution, since we have to acknowledge some limitations and general reflections on the phenomenon of opting out. Our findings stem from the perspectives of the subjects involved, all of whom voluntarily participated in our study and had 5 years of corporate experience, a fact which reflects a bias in the study design. Therefore, the generalizability of our results is limited to those who had the personal motivation to opt to narrate their stories, which might have led to a bias in favor of more successful subjects the ones who managed to maintain a career and who have a confident story to share. It is 
probable that there are other types of opting out from "moral" career paths, for instance in the field of social and sustainable entrepreneurship, which might reveal differing styles of selfemployment or outright alternative stories about opting out in a non-entrepreneurial milieu. Also, we restricted our data collection to a specific group of participants from the German context, and we limited it to a certain number of participants. However, our data fully capture some main aspects of the perspective set forth by those who opt-out and why they did so, proposing initial indications for future developments and a starting point for comparison and possible typologies. Indeed, future studies could examine our perspectives by enlarging the sample to ensure a more international set of participants, and to offer financial incentives for participation in order to reduce the self-selection bias. Nevertheless, these findings can be interpreted as offering initial arguments that may be used both to explore individual processes of work individualization and to interrogate contemporary corporate conditions. Ultimately, these findings can offer initial insights on the utopian ideological thought on work and self-realization that represents a neglected topic in the study of individuals, work, organizations, and the subject's negotiation and incorporation of a neoliberal context and logic. It is shown that individually and socially selfactualized subjects emancipate due to personal achievements and with the aim to negotiate the professional and private self, yet remain within the scope of neoliberal principles and economic success, which is not seen as critical but, again, as a source of identity.

\section{Conclusion}

This paper presents a critical psychological view of the opting-out process. Our critical lens demonstrates, first, that corporate working conditions do not serve the subject's wish for selfactualization. On the contrary, they reduce well-being, authenticity, ability to thrive, and can even genuinely threaten health and well-being, leading to severe personal crises that can only be overcome by the diligent and most successful individuals within a group of peers, if they choose to gain agency through self-employment. Moreover, the overall stance of the subjects in our study suggests that family-friendly values, the search for meaning, and the avoidance of masculine traditions are proven possible while maintaining neoliberal ideals; The subjects continued economic success after opting out and implementing values as true flexibility and "female" (non-masculine) work styles shows, these traditions are obsolete to maintain objective economic success, a proven case that radically is questioning working traditions in corporations by their means. Second, the critical perspective presented here shows that the subjects' reflections on their corporate experiences and their emancipatory action to free themselves of it are limited to their criticism of corporate working conditions and their restrictive agency within it. However, they remain restrictive (compliant and even harder-working) vis-a-vis the larger frame of neoliberal logic. Deepen our understanding of opting out as an emancipatory act, further theoretical and critical studies on the questioning of corporate working conditions, on their purported necessity and legitimation, and on their true consequences for subjects - especially when those consequences are hidden behind certain notions about liberalization and freedom - are urgently needed. Other forms of opting out (such as downshifting or autarky living), which go beyond the naturalized and incorporated neoliberal ideology and which may or may not constitute acts of resistance to a restrictive liberal ideology, also remain to be studied.

\section{Appendix}




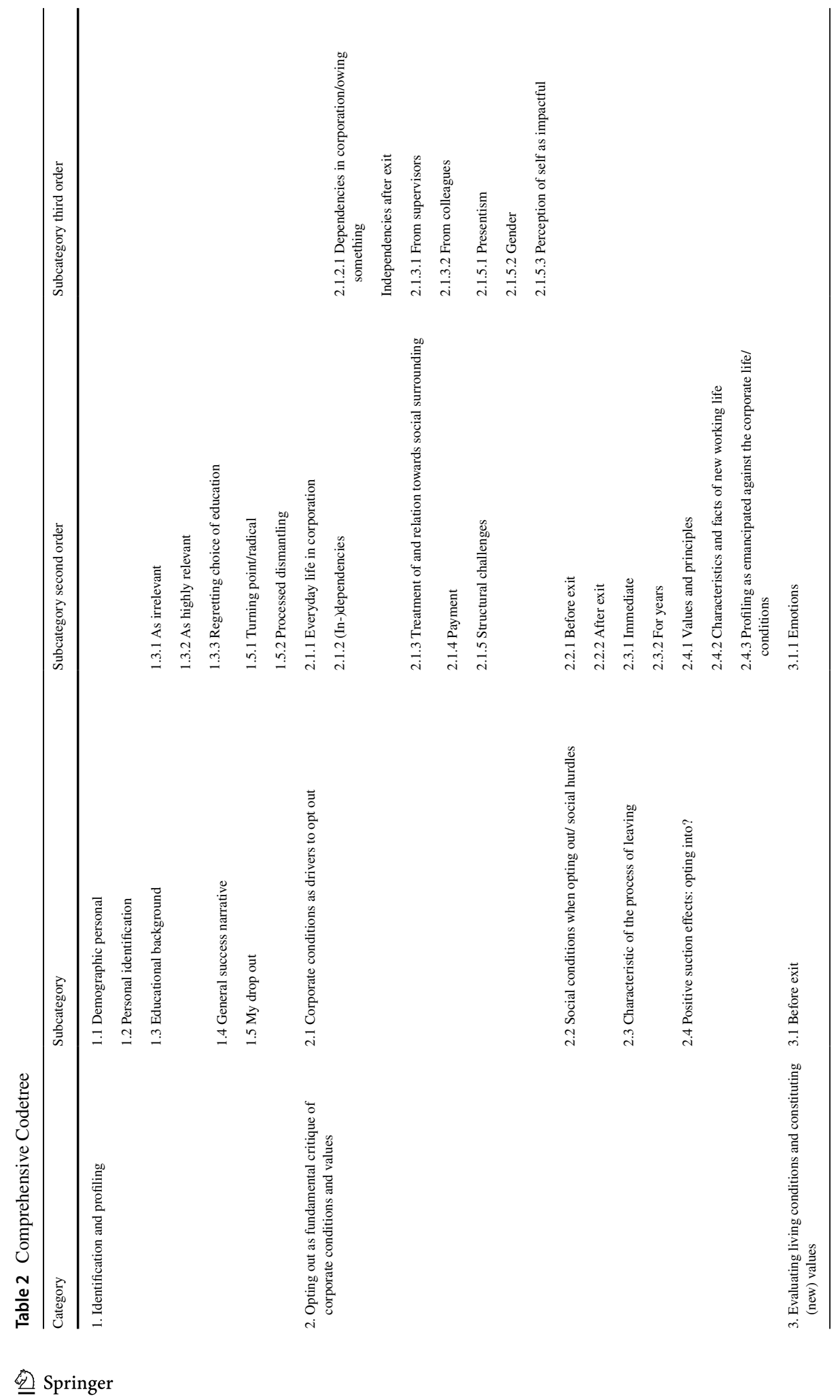




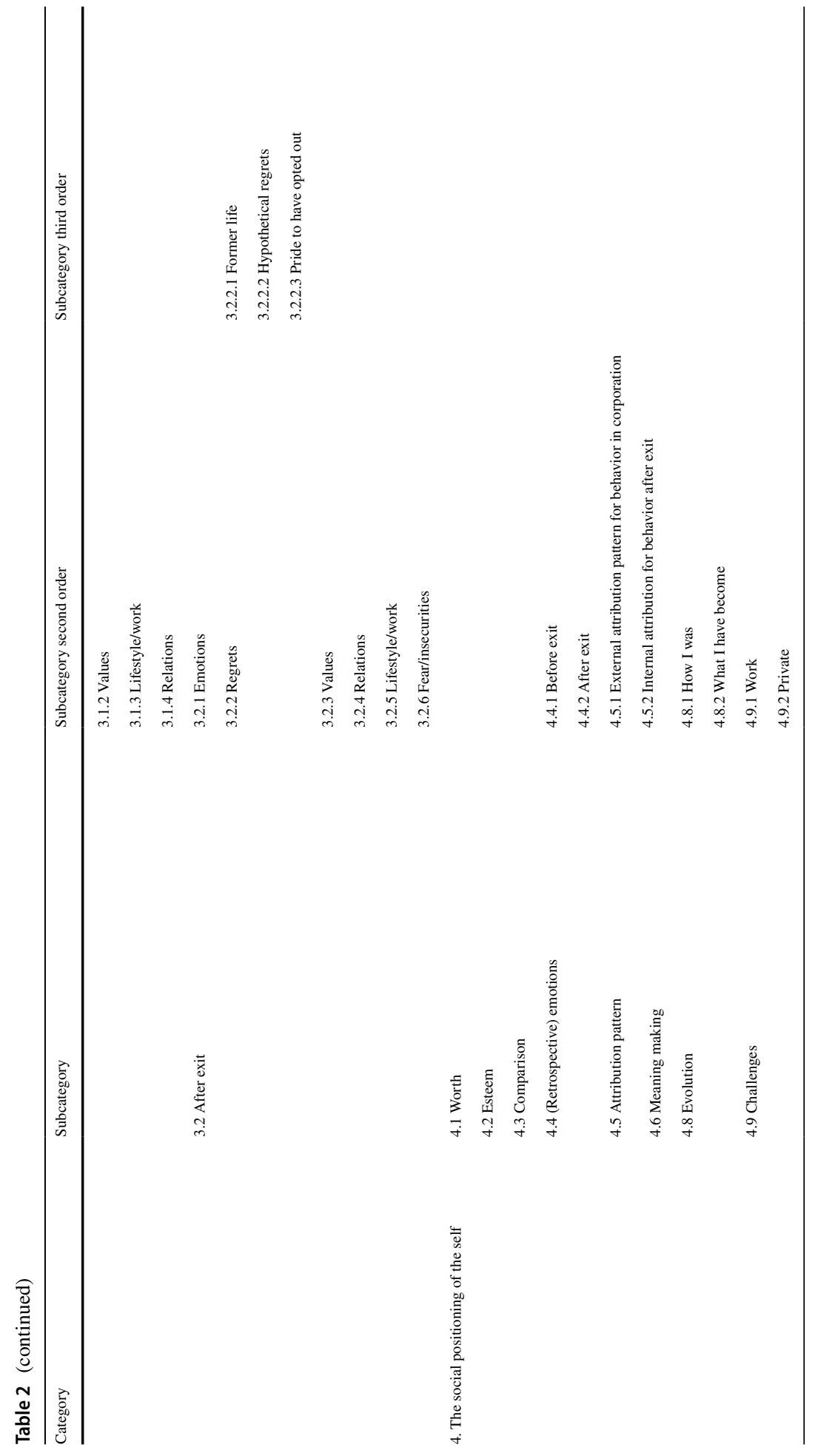


Table 3 Additional data examples

Category Data example

Identification and profiling

Opting out as fundamental critique of corporate conditions
"We have always been entrepreneurs, it runs in the family and me being in corporations was an alienated state after all." (8; 179-181)

"I did my masters but already back then I knew, this was wrong, I should have gone for the own business from the start, on the other hand, I learned a lot and how would i have succeeded without the knowledge and money from corporate life." (4; 21-24)

"I guess something more creative would have been better for me (...). Probably I also chose this direction [management] to please my father to a certain degree." (7; 22-24)

"I could not have done it without the knowledge and economic capital I gained from working for corporate." (19; 220-223)

"I was given more people and more money, but I just functioned." (1; 68)

"Boring! But you go along and play the game." (2; 76-77)

"It was exhausting always saying the right thing. My strategy was not to say anything anymore. Adapt. Adapt. Adapt." (5; 71-72)

"I was unhappy inside. I knew it was meaningless." $(10 ; 20-21)$

"I just made money and I did not grow anything. You deliver but you have nothing in return. Your worth may be even decreasing by time, by becoming older." (14; 22-24)

"How people and managers were treated. Being dependent on the position and being abused and used." (17; 134-135)

"After a few years, everything was going great. After some time I noticed, quite suddenly, that I don't agree with the corporate values. Working conditions were awful, we had to be there all day, nobody was happy. Not the employees, not the customers, the price was broken families for all of us and I suddenly saw that coming, I learned it was the system immanent and I started hating the company." (20; 91-94)

"I grew tired of and frustrated by time and energy consuming processes and hierarchies within a corporate structure." (2; 83-84)

"In the end I was supposed to only lead by numbers." $(7 ; 32)$

"The company did not trust my loyalty." (3; 33-34)

"My excitement was lowered when I realized that even though she told me my proposal was great, she had clearly not read it. Also she did not really want to hear about it." (1; 43-45)

"And all of a sudden I had a huge corner office. The uncomfortable part was, I did not feel I deserved it more than anybody else." (6; 111-112) 
Table 3 (continued)

\begin{tabular}{|c|c|}
\hline Category & Data example \\
\hline $\begin{array}{l}\text { Evaluating living conditions and constituting (new) } \\
\text { values }\end{array}$ & $\begin{array}{l}\text { "Yet it took me a full year to quit." }(8 ; 58-59) \\
\text { "It took me one year to realize I wasn't actually trying } \\
\text { to fulfill the position, but I was using the time to } \\
\text { make excuses. On my } 47 \text { th birthday I quit after one } \\
\text { year on the job." ( } 6 ; 46-48) \\
\text { "From the first idea to me leaving the company it was } \\
\text { five to six years." ( } 4 ; 24-25) \\
\text { "After months of internal fights and reflections I } \\
\text { asked myself the question "Is this what I wanted } \\
\text { to achieve and if not, what can I change in order to } \\
\text { make this my dream?" ( } 7 \text {; } 40-41) \\
\text { "I travelled for } 14 \text { months and then came home. Not } \\
\text { doing anything wasn't for me either. I tried a couple } \\
\text { of things." (6; 49-50) }\end{array}$ \\
\hline The social positioning of the self & $\begin{array}{l}\text { "I was always different from all the other kids, from } \\
\text { all the others at university and later alienated in the } \\
\text { corporation. It was always meant to be for me to } \\
\text { become self employed, to be a leader of something } \\
\text { innovative." ( } 20 ; 51-53) \\
\text { "Opting out is not for everybody. I saw many failures. } \\
\text { everybody has the idea but who is able to put it } \\
\text { though?" }(19 ; 191-192) \\
\text { "The right decision where I choose the destination of } \\
\text { a friendly work environment." }(2 ; 99-100) \\
\text { "This attitude is not owed to laziness." }(8 ; 72) \\
\text { "But still maybe when I fail maybe I will regret }(. . .) \text { " } \\
\text { (4; } 128)\end{array}$ \\
\hline
\end{tabular}

Acknowledgements We gladly acknowledge Juliane Gökes who contributed to this paper with parts of the data collection.

Funding Open access funding provided by Università degli Studi di Verona within the CRUI-CARE Agreement.

Open Access This article is licensed under a Creative Commons Attribution 4.0 International License, which permits use, sharing, adaptation, distribution and reproduction in any medium or format, as long as you give appropriate credit to the original author(s) and the source, provide a link to the Creative Commons licence, and indicate if changes were made. The images or other third party material in this article are included in the article's Creative Commons licence, unless indicated otherwise in a credit line to the material. If material is not included in the article's Creative Commons licence and your intended use is not permitted by statutory regulation or exceeds the permitted use, you will need to obtain permission directly from the copyright holder. To view a copy of this licence, visit http://creativecommons.org/licenses/by/4.0/.

\section{References}

Bal, M. P., \& Dóci, E. (2018). Neoliberal ideology in work and organizational psychology. European Journal of Work and Organizational Psychology, 27(5), 536-548. https://doi.org/10.1080/1359432X.2018. 1449108

Batt, R. \& Colvin, A. (2011). An employment systems approach to turnover: Human resources practices, quits, dismissals, and performance. Academy of Management Journal 54(4): 695-717. https://www. doi-org.ezproxy.library.bi.no/10.5465/AMJ.2011.64869448

Belkin, L. (2003). The opt-out revolution. Available at: https:/www.nytimes.com/2003/10/26/magazine/theopt-out-revolution.html.

Biese, I. (2017). Opting out and in: On women's careers and new lifestyles (1st ed.). Routledge. https://doi. org/10.4324/9781315637006 
Biese, I., \& Choroszewicz, M. (2019). Opting out: Professional women develop reflexive agency. Equality, Diversity and Inclusion, 38(6), 619-633. https://doi.org/10.1108/EDI-06-2018-0097

Binkley, S. (2014). Happiness as enterprise: An essay on neoliberal life. Suny Press

Carland III, J. W., Carland Jr, J. W., Carland, J. A. C., \& Pearce, J. W. (1995). Self-actualization: The zenith of entrepreneurship. Journal of Small Business Strategy, 6(1), 53-66.

Cossman, B. (2009). The "Opt Out Revolution" and the changing narratives of motherhood: Self governing the work/family conflict. Journal of Law and Family Studies, 11.

Frkal, R. A., \& Criscione-Naylor, N. (2021). Opt-out stories: Women's decisions to leave corporate leadership. Gender in Management, 36(1), 1-17. https://doi.org/10.1108/GM-09-2019-0154

Follmer, E. H., Talbot, D. L., Kristof-Brown, A. L., Astrove, S. L., \& Billsberry, J. (2018). Resolution, relief, and resignation: A qualitative study of responses to misfit at work. Academy of Management Journal, 61(2), 440-465.

Gergen, K. (2011). The self as social construction. Psychological Studies, 56(1), 108-116. https://doi.org/ 10.1007/s12646-011-0066-1

Gergen, K. (2014). The saturated self: Dilemmas of identity in contemporary life. In Essays and reviews: 19592002 (pp. 318-320). Princeton: Princeton University Press. https://doi.org/10.1515/9781400848393-062

Glynos, J., \& Howarth, D. (2007). Logics of critical explanation in social and political theory. Routledge.

Holzkamp, K. (1983/2003). Grundlegung der Psychologie. Campus.

Holzkamp, K. (1990). Worauf bezieht sich das Begriffspaar »restriktive/verallgemeinerte Handlungsfähigkeit «? $\mathrm{Zu}$ Maretzkys vorstehenden »Anmerkungen«. Kritische Psychologie, 26, 35-45.

Hoobler, J. M., Wayne, S. J., \& Lemmon, G. (2009). Bosses' perceptions of family-work conflict and women's promotability: Glass ceiling effects. Academy of Management Journal, 52(5), 939-957.

Kossek, E., Su, R. \& Wu, L. (2016). “Opting Out” or "Pushed Out”? Integrating perspectives on women's career equality for gender inclusion and interventions. Journal of Management 43(1): 228-254. Available at: https://doi.org/10.1177/0149206316671582.

Marvakis, A. (2019). The neoliberal framing of (critical) psychology. Annual Review of Critical Psychology, 16, 22-52.

Mayring, P. (1991). Qualitative Inhaltsanalyse. In U. Flick, E. V. Kardoff, H. Keupp, L. V. Rosenstiel, \& S. Wolff (Eds.), Handbuch qualitative Forschung: Grundlagen, Konzepte, Methoden und Anwendungen (pp. 209-213). München: Beltz - Psychologie Verl. Union.

Mayring, P. (2015). Qualitative Inhaltsanalyse. Grundlagen und Techniken. Beltz: Weinheim.

McKie, L., Biese, I., \& Jyrkinen, M. (2013). Women opting in to self-employment. Gender, Work and Organization, 20, 184-196. https://doi.org/10.1111/gwao.12019

Paustian-Underdahl, S. C., Eaton, A. A., Mandeville, A., \& Little, L. M. (2019). Pushed out or opting out? Integrating perspectives on gender differences in withdrawal attitudes during pregnancy. Journal of Applied Psychology, 104(8), 985-1002. https://doi.org/10.1037/ap10000394

Rose, N. (1996). Governing the soul. Free Association Books.

Schraube, E., \& Højholt, C. (2016). Psychology and the conduct of everyday life (7. Aufl.). Routledge.

US Bureau of Labor Statistics. (2014). Employment characteristics of families, available at: https://www. bls.gov/bls/cpswomendata.htm. (accessed January 5, 2022).

Wilton, S. (2017). Mompreneurs, leaning in and opting out: Work/family choices under neo-liberalism. Digital Feminist Counter-Publics. Atlantis Critical in Gender Culture and Social Justice. 38,(2): Affecting Feminist Literary \& Cultural Production \& Whoops i am a lady on the internet.

Zimmerman, L. M., \& Clark, M. A. (2016). Opting-out and opting-in: A review and agenda for future research. Career Development International, 21(6), 603-633. https://doi.org/10.1108/ CDI-10-2015-0137

Publisher's Note Springer Nature remains neutral with regard to jurisdictional claims in published maps and institutional affiliations.

\section{Authors and Affiliations}

\section{Francesco Tommasi ${ }^{1}$. Johanna L. Degen ${ }^{2}$}

1 Department of Human Sciences, University of Verona, Verona, Italy

2 Department of Psychology, European University of Flensburg, Flensburg, Germany 